\title{
Sprint Interval Training Improves Aerobic and Anaerobic Power in Trained Female Futsal Players
}

\author{
Fatemeh Beyranvand (Corresponding author) \\ Department of Physical Education and Sport Science, Islamic Azad University, Borujerd Branch, Borujerd, Iran \\ E-mail: Fatima.Beyranvand@gmail.com
}

Received: 11-03- 2017

Accepted: 28-04- 2017

Published: 30-04- 2017

doi:10.7575/aiac.ijkss.v.5n.2p.43

URL: http://dx.doi.org/10.7575/aiac.ijkss.v.5n.2p.43

\begin{abstract}
Background: Various sprint interval training (SIT) programs have been used with athletes from a wide range of sports to evaluate its effects on physiological and performance adaptations. However, information regarding the effect of a short period of SIT on physiological adaptations of trained female futsal players is limited. Objective: This study evaluated the influence of sport specific SIT on anaerobic power and aerobic power in trained female futsal players. Method: Several aspects of $\dot{\mathrm{V}}_{2 \max }$ and Wingate-based power were measured after SIT program performed for 4 weeks. Following pre-test, 16 trained female futsal players $\left(\dot{\mathrm{V}}_{2 \max }=41.21 \pm 3.35 \mathrm{ml} . \mathrm{kg}-1 . \mathrm{min}-1\right)$ were randomized to either an intense exercise training consisting of sets of $5 \times 40$ meter maximum sprint efforts interspersed by a 10 -second rest between sprints $(3,4,5,6$ sets/session from 1 st to 4 th week respectively with 3 minutes of recovery between sets), performed two sessions a week over 4 weeks $(n=8)$ or a usual training control group $(n=8)$. Results: Significant (except as shown) improvements ( $\mathrm{p}$ < 0.05) after SIT were seen in: $\dot{\mathrm{V}} \mathrm{O}_{2 \max }(5.8 \%), \mathrm{v}_{\mathrm{V}} \mathrm{O}_{2 \max }(6 \%), \dot{\mathrm{V}} \mathrm{O}_{2} / \mathrm{HR}(6.5 \%)$, peak power output (PPO) (7.6\%), and mean power output (MPO) (14.9\%), but no significant change was found in Heart rate at $\dot{\mathrm{V}}_{2 \max }$. Also, no significant enhancement in mentioned variables was found in the CON group. Conclusion: Present results indicate 4 weeks of sprint interval training program with low volume is associated with improvements in $\dot{\mathrm{V}}_{2 \max }$, $\mathrm{v} \dot{\mathrm{V}} \mathrm{O}_{2 \max }, \dot{\mathrm{VO}}_{2} / \mathrm{HR}, \mathrm{PPO}$, and MPO in trained female futsal players.
\end{abstract}

Keywords: $\dot{\mathrm{V} O} 2 \mathrm{max}$, anaerobic power, conditioning, running, training technique

\section{Introduction}

Performing high-intensity "sprint"-type interval training (SIT) have been shown to improve variables associated with physiological function and performance over several weeks (Burgomaster et al., 2005). The direction and magnitude of these adaptations in different variables depend on intensity and sprint frequency, recovery time between efforts, as well as duration of sprints (Burgomaster et al., 2005; Gist et al., 2014). Coaches try to enhance the training effectiveness through modification of the intensity and duration of both the recovery phases and training. This optimization is based on the specific sport in which the participant competes (Sheykhlouvand et al., 2016). Sprint interval training, in a variety of forms, has been used with cyclists, swimmers, runners, and rowers to examine the effects on physiological and hematological adaptations (Driller et al., 2009). However, information regarding the effect of a short period of SIT on physiological adaptations of trained female futsal players is limited. Futsal is a ball sport with two teams of five players. One of players is the goalkeeper and other 4 players act as outfield players). Each futsal team has 7 substitutes (a goalkeeper and six outfield players). During the official match unlimited substitutions can be made. This indoor soccer is played on a $40 \times 20 \mathrm{~m}$ indoor hall with $3 \times 2 \mathrm{~m}$ goals. The competition time is 2 periods of 20 minutes, and the timer is stopped for some events (Alvarez et al., 2009). Although anaerobic energy production is the predominant energy system for highly intense activities with repeated efforts over short durations, aerobic power is key component for short-term recovery intervals during the match (Karahan, 2012). In another study Barbaro-Alvarez et at (2008) in a competition analysis through monitoring of heart rate revealed that futsal is an intense intermittent sport with important demands on the anaerobic and aerobic metabolism. Games of small-sided (mainly 5 vs. 5) recently has been indicated as a valid type of training to enhance aerobic fitness in football. Thus, it could be concluded that trained futsal players may have a well-developed aerobic capacity as a secondary to training and match participation (Alvarez et al., 2009). Hence, it is of practical interest for coaches to simultaneously improve these capacities in their athletes (Alvarez et al., 2009; Oliveira et al., 2013). Moreover, futsal players most of the times need to be at peak performance for matches several times over a yearly training period and require a training program to get fitness in a short period. As lack of time is a universally cited barrier for performing some specific conditioning programs during heavy and prolonged schedule of competition among futsal players, the time-efficient dimension of SIT might have significant application for them to achieve competitive fitness in short time frame (Gist et al., 2014). Like the nature of SIT, futsal players require to perform relatively intensive activities and more sprints during a match (Oliveira et al., 2013). Hence, running-based SIT might be a sport-specific prescription for futsal to improve anaerobic power and cardiorespiratory fitness (Alvarez et al., 2009; Oliveira et al., 2013). Accordingly, the purpose of our study was to determine whether 4 weeks of SIT would improve 
selected aerobic and anaerobic performance indices in trained female futsal players. It was hypothesized that runningbased SIT would provide sufficient stimulus to enhance aerobic and anaerobic performance adaptations.

\section{Method}

\subsection{Participant}

Sixteen trained female futsal players (age $=29.6 \pm 2.1$ years; height $=166.5 \pm 6.1 \mathrm{~cm}$; body mass $=57.4 \pm 9.3 \mathrm{~kg}$; $\mathrm{BMI}$ $=21.4 \pm 1.1 \mathrm{~kg} \cdot \mathrm{m}^{-2}$; training experience $=6 \pm 3$ years) volunteered to take part in the experiment. Before the participation, the experimental protocols and probable risks were cleared fully to the participants written informed consent was received. Participants were randomly divided to an SIT group or control (CON) group using G*Power software (version 3.1.9.2) ( $\alpha$ level $=0.05$ and effect size $=0.08$ ). Research Ethic Boards of Islamic Azad University of Borujerd approved this study, and the study conformed to the Declaration of Helsinki.

\subsection{Procedures}

2.1.1 The multi-stage 20-m shuttle run fitness test (20mMSFT).

This test was developed by Léger and Lambert (1982) and it has been used as a valid method for determination of $\dot{\mathrm{V}} \mathrm{O}_{2 \max }$. It involved running between two lines set $20 \mathrm{~m}$ apart at a pace dictated by a recording emitting tones at appropriate intervals. Velocity was $8.5 \mathrm{~km} \cdot \mathrm{h}-1$ for the first minute, which increased by $0.5 \mathrm{~km} \cdot \mathrm{h}-1$ every minute thereafter (Paradisis et al., 2014). Achieved score by the subject was the number of 20-m shuttles completed prior to the subject either volitional withdrawn from the test, or fail to be within $3 \mathrm{~m}$ of the end lines on two consecutive tones. Heart rates were continuously recorded throughout the test (Polar, Electro Oy, Finland). $\mathrm{v}^{\mathrm{V}} \mathrm{O}_{2 \max }$ (the minimal speed at which the participant was running when $\dot{\mathrm{VO}}_{2 \max }$ revealed) was assessed according to Paradisis et al. (2014).

\subsubsection{Anaerobic power.}

Peak power output (PPO) and mean power output (MPO) were assessed by a 30-second all-out effort (Wingate test) on a cycle ergometer (894E, Monark, Sweden) against a resistance of $0.075 \mathrm{~kg} \cdot \mathrm{kg}-1$ body weight (MacDougall et al., 1998). The participants tried to get optimal comfort and pedaling efficiency. Participants reached maximum pedaling speed against the ergometer's inertial resistance over 2 seconds before the load was added and the electronic revolution counter was activated. Pedaling as fast as possible during the 30-second test, participants were verbally encouraged. Using a data-acquisition system, the 5 second PPO, and 30 second MPO were subsequently calculated (Farzad et al., 2011).

\subsubsection{Training program.}

Training for both groups commenced $\sim 48$ hours after the last baseline measurements. The training program is presented in Table 1.

Table 1. Training program for each group $(\mathrm{N}=8$ for each group)

\begin{tabular}{lll}
\hline Days of week & SIT group & CON group \\
\hline Monday & Futsal training & Futsal training \\
Tuesday & Sprint interval training (MO) & Weight training \\
& Weight training (EV) & \\
Wednesday & Futsal training & Futsal training \\
Thursday & Sprint interval training (MO) & Futsal training \\
& Futsal training (EV) & \\
Friday & Rest & Rest \\
Saturday & Weight training & Weight training \\
Sunday & Sprint interval training (MO) & Futsal training \\
& Futsal training (EV) & \\
\hline MO = morning (10 a.m.); EV = evening (4 p.m.).
\end{tabular}

Both groups performed the same futsal training sessions including technique drills and tactic practice 4 times a week. In addition, both groups participated in 2 sessions of weight lifting training per week in 3 sets of 8 repetitions at $70 \% \times 1$ repetition maximum (movements including back squat, bench press, leg extension, bicep curl, and leg curl). The SIT group followed a running-based SIT program in addition to this training. Including sets of 5 40-m (futsal play area length) all-out efforts with a 10-second rest between sprints, this program was performed in 3 sessions a week. During initial week, 3 sets were completed, with a rest of 3-minutes between sets. One set was added in each subsequent week with the 3-minute recovert between each set. Each SIT session was started with a 10-minute warm-up and continued by sets (3-6) of $5 \times 40-\mathrm{m}$ all-out sprints with 3 minutes of rest between sets and then followed by a 10-minute cool-down period. 


\subsection{Statistical Analysis}

All results are reported as mean \pm SD. A two-factor mixed ANOVA, with the between factor "group" (training, control) and repeated factor "trial" (pre-training, post-training) was used to analyze of aerobic and anaerobic power data. Significant main effects or interactions were subsequently analyzed using a Tukey’s post-hoc test. Level of alpha for statistical significance was set at $\mathrm{p} \leq 0.05$.

\section{Results}

\subsection{Aerobic Power}

After the 4-week training period, the change in $\dot{\mathrm{V}} \mathrm{O}_{2 \max }$ in SIT group was significantly greater compared with the change in CON group $(p=0.04)$. $\dot{\mathrm{V}} \mathrm{O}_{2 \max }$ was significantly increased by $5.8 \%$ in SIT group $(\mathrm{p}=0.01)$ compared with pretraining, but no significant changes took place in CON group $(\mathrm{p}=0.1)$ (Table 2).

Table 2. Pre-training vs. post-training values for aerobic capacity

\begin{tabular}{|c|c|c|c|c|c|c|}
\hline \multirow[b]{2}{*}{ Variables } & \multicolumn{3}{|l|}{ SIT } & \multicolumn{3}{|l|}{ Control } \\
\hline & Pre & post & $\mathrm{P}$ value & Pre & post & $\mathrm{P}$ value \\
\hline$\dot{\mathrm{V}} \mathrm{O}_{2 \max }(\mathrm{ml} . \mathrm{kg}-1 . \min -1)$ & $41.67(2.6)$ & $44.08(2.4) * \dagger$ & 0.01 & $40.75(4.1)$ & $41.23(3.7)$ & 0.10 \\
\hline $\mathrm{v} \dot{\mathrm{V}} \mathrm{O}_{2 \max }(\mathrm{km} \cdot \mathrm{h}-1)$ & $13.4(0.4)$ & $14.2(0.3) *$ & 0.02 & $13.6(0.6)$ & $13.7(0.2)$ & 0.60 \\
\hline$\dot{\mathrm{V}} \mathrm{O}_{2} / \mathrm{HR}$ (ml.b.min-1) & $13.6(1.2)$ & $14.5(1.1) * \dagger$ & 0.03 & $12.9(2.6)$ & $13.0(2.5)$ & 0.20 \\
\hline $\mathrm{HR} @ \dot{\mathrm{V}} \mathrm{O}_{2 \max }($ b.min-1) & $179.7(6.2)$ & $181.6(5.9)$ & 0.20 & $183.0(3.4)$ & $183.3(3.2)$ & 0.60 \\
\hline
\end{tabular}

Data are means $( \pm$ S.D. $)$. Maximum oxygen uptake $\left(\dot{\mathrm{VO}}_{2 \max }\right)$, running speed at $\dot{\mathrm{V}}_{2 \max }\left(\mathrm{v}_{\mathrm{V}} \mathrm{O}_{2 \max }\right)$, heart rate at $\dot{\mathrm{V} O}{ }_{2 \max }$ $\left(\mathrm{HR} @ \dot{\mathrm{V}} \mathrm{O}_{2 \max }\right)$, and $\mathrm{O}_{2}$ pulse $\left(\dot{\mathrm{VO}}_{2} / \mathrm{HR}\right)$.

* Significantly greater than pre-training value $(\mathrm{p}<0.05)$.

$\dagger$ Significantly different change compared with control group $(\mathrm{p}<0.05)$.

There was a near-significant difference between changes in $\mathrm{v}_{\mathrm{V}} \mathrm{O}_{2 \max }$ in SIT and CON groups $(\mathrm{p}=0.06)$. $\mathrm{v} \dot{\mathrm{V} O} \mathrm{O}_{2 \mathrm{xax}}$ was significantly enhanced from pre- to post-training by $6.0 \%$ in SIT group $(\mathrm{p}=0.02)$, but not in CON group (p = 0.6) (Table 2). The change in $\dot{\mathrm{VO}}_{2} / \mathrm{HR}$ in the SIT group was significantly greater compared to the change in CON group ( $\mathrm{p}$ $=0.01)$. $\dot{\mathrm{VO}}_{2} / \mathrm{HR}$ significantly increased in the SIT group by $6.5 \%(\mathrm{p}=0.03)$ compared with pre-training, but no significant changes were seen in the CON group $(\mathrm{p}=0.2)$ (Table 2). SIT and CON did not significantly change $\mathrm{HR} @ \dot{\mathrm{V}}_{2 \max }$ over time $(\mathrm{p}=0.2$ and $\mathrm{p}=0.6$, respectively) (Table 2). No pre-training difference was occurred between groups for aforementioned variables.

\subsection{Anaerobic Power}

After the 4-week training period, the change in PPO in SIT group was significantly greater compared with the change in CON group $(\mathrm{p}=0.01)$. PPO was significantly increased by $7.6 \%$ in SIT group from pre- to post-training (Pre-training: $480.3 \pm 33.8$ vs. Post-training: $516.9 \pm 44.8 \mathrm{~W}, \mathrm{p}=0.02$ ), but no significant changes were observed in CON group from pre- to post-training (Pre-training: $489.2 \pm 50.3$ vs. Post-training: $500.7 \pm 33.7 \mathrm{~W}, \mathrm{p}=0.3$ ) (Figure 1).

There was a significant difference between changes in MPO in SIT and CON groups $(\mathrm{p}=0.02)$. MPO was significantly enhanced from pre-training to post-training by $14.9 \%$ in SIT group (Pre-training: $383.7 \pm 41.8$ vs. Post-training: $440.9 \pm$ 34.6 W, $\mathrm{p}=0.01$ ), but not in CON group (Pre-training: $396.5 \pm 46.8$ vs. Post-training: $415.3 \pm 38.5 \mathrm{~W}, \mathrm{p}=0.1)($ Figure 1).

No pre-training difference was observed between groups for aforementioned variables.
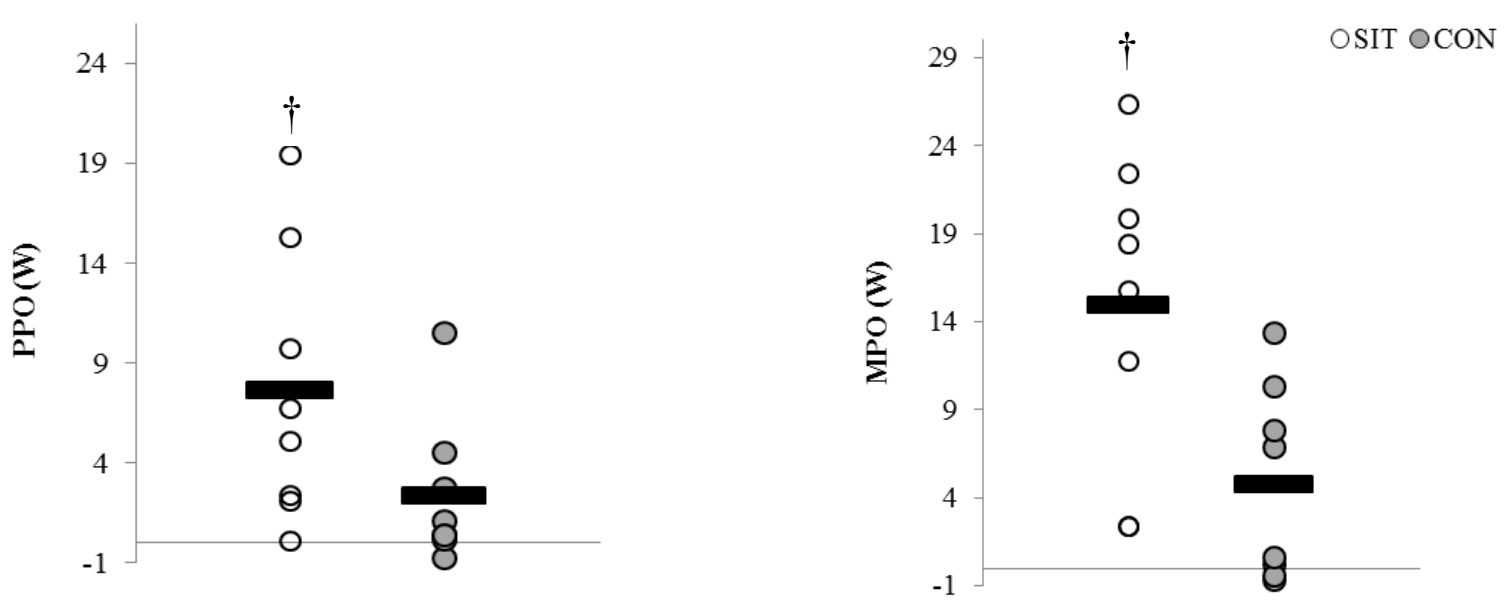

Figure 1. Effect of 4 weeks of SIT or CON on PPO and MPO. Circles indicate individual percentage change from baseline and horizontal bars indicate mean group percentage change from baseline. $\mathrm{n}=8$ for SIT and $\mathrm{n}=8$ for CON. $\dagger$ Significantly different change compared to CON group $(\mathrm{p}<0.05)$. 


\section{Discussion}

The present study demonstrates that 4 weeks of low-volume, sprint interval training is a practical and time-efficient strategy to improve sport-specific physiological variables in trained female futsal players. SIT significantly improved

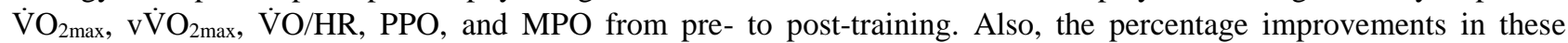
variables (except $\mathrm{v} \dot{\mathrm{V}} \mathrm{O}_{2 \max }$ ) were all significantly greater following SIT when compared with $\mathrm{CON}^{\mathrm{V}} \mathrm{O}_{2 \mathrm{max}}$ is one of the primary determinants of aerobic endurance performance (Sheykhlouvand et al., 2016). In line with our hypothesis, our participants revealed significantly higher relative $\dot{\mathrm{VO}}_{2 \max }$ compared with pre-training. Our findings support Rowan et al. (2012) who reported increases in $\dot{\mathrm{VO}}_{2 \max }$ after 5 weeks of running SIT $(5 \times 30$ seconds all-out, 4.5 min recovery, twice a week) in female soccer players. In another study on trained individuals, Laursen et al. (2002) have demonstrated significant improvement in $\dot{\mathrm{VO}}_{2 \max }$ after 4 weeks of cycling SIT $(12 \times 30$ seconds at $175 \%$ PPO, 4.5 min recovery). The enhancement of $\dot{\mathrm{V}}_{2 \max }$ following SIT could be caused by both oxygen use by active tissues (i.e., increases in capillarization, local enzymatic adaptations, and mitochondrial density/volume) and oxygen delivery (i.e., increases in $\mathrm{SV}$ as higher $\mathrm{V}_{2} / \mathrm{HR}$ recorded in our study) adaptations (Driller et al., 2009). Because, previous studies indicated a significant relationship between $\mathrm{SV}$ and $\dot{\mathrm{VO}} / \mathrm{HR}$ (Laffite et al., 2003), we can probably assume that the grater $\dot{\mathrm{V}} \mathrm{O}_{2 \mathrm{max}}$ in the SIT group may in part be due to an increased SV. This supports previous researches (Farzad et al., 2011; Astorino et al., 2012) showing that SIT performed with different protocols improved $\dot{V}_{2} / \mathrm{HR}$ over 3-4 weeks. On the other hand, it has been shown that sprint interval training improves enzyme activities of anaerobic and aerobic metabolism (Rodas et al., 2000; Burgomaster et al., 2005). A limitation of the present study was no muscle biopsies were taken to directly determine muscle oxidative capacity. Collectively, along with aforementioned studies, our findings support the theory of Driller et al. (2009) who noted that the improvement of $\dot{\mathrm{V}}_{2 \max }$ following intense interval training may be attributed to both peripheral and central adaptations.

$\mathrm{v} \mathrm{V}_{2 \max }$ significantly increased following 4 weeks of SIT. These findings are in agreement with previous research reporting an enhancement in $\mathrm{vVO}_{2 \max }(3$ to $10 \%$ ) after intense interval training in subjects of varying aerobic capacities (Esfarjani et al., 2007; Smith et al., 1999). Neural adaptations (Creer et al.,2004) and improvements in running economy (Esfarjani et al., 2007) may be responsible for the improvement in $\mathrm{v}_{\mathrm{V}} \mathrm{O}_{2 \max }$. The training in our experiment resulted in a significant increase in PPO and MPO. These results support previous studies (Burgomaster et al., 2005; Gibala et al., 2006) reporting an improvement in peak and mean anaerobic power following SIT (4-7 all-out 30-second Wingate trials with 4 minutes of recovery 3 sessions per week). Stangier et al. (2016) demonstrated that improving peak and mean power is necessary to enhance the kinetic energy at the start of a race. Over short distances, futsal players show considerable variations in speed. Thus, high power outputs and a well-developed anaerobic glycolytic energy system are important factors required to respond to changes in race pace during match. Increased proportion of muscle buffering capacity (Laursen et al., 2002b), muscle phosphocreatine concentration (Farzad et al., 2011), and adaptation in recruitment or activation of motor units (Van Cutsem et al., 1998) are possible explanations for our findings. A limitation of the present study could be the SIT group completed more training time than the CON group. Although training duration was not the same between groups, "duration" of very low-volume SIT program in a 4-week period (only 25 minutes of very intense exercise) was unlikely large enough to affect such physiological changes alone. Hence, it is likely that other factors related to the nature of SIT (intensity, frequency, and duration of sprint efforts as well as the recovery time between each effort) contributed to the magnitude of these changes rather than the extra training time ( 80-160 sec SIT/session) of SIT group compared with the CON group.

\section{Conclusion}

The present study showed that a 4-week sprint interval training program with improved $\dot{\mathrm{V}} \mathrm{O}_{2 \max }, \mathrm{v} \dot{\mathrm{V}} \mathrm{O}_{2 \mathrm{max}}, \dot{\mathrm{V} O} / \mathrm{HR}$, PPO, and MPO in trained female futsal players. Therefore, This SIT protocol could be considered as specific training programs to improve aerobic performance and anaerobic power in female futsal players under the conditions of the present study. As such training programs have a very low volume and high intensity, futsal players and their coaches can use this type of training prescriptions when they have to acquire several physical peaks over a yearly period, especially when the target is to enhance performance in a short period.

\section{References}

Alvarez, J.C., D'Ottavio, S., Vera, J.G., \&bCastagna, C. (2009) Aerobic fitness in futsal players of different competitive level. Journal of Strength and Conditioning Research, 23(7), 2163-2166. https://doi.org/ 10.1519/JSC.0b013e3181b7f8ad

Astorino, T.A., Allen, R.P, Roberson, D.W., \& Jurancich, M. (2012). Effect of high-intensity interval training on cardiovascular function, $\dot{\mathrm{VO}}_{2 \max }$, and muscular force. Journal of Strength and Conditioning Research, 26(1), $138-145$. https://doi.org/10.1519/JSC.0b013e318218dd77

Barbero-Alvarez, JC, Soto, VM, Barbero-Alvarez, V, and Granda-Vera, J. (2008). Match analysis and heart rate of futsal players during competition. Journal of Sports Science, 26(1): 63-73. https://doi.org/10.1080/02640410701287289

Burgomaster, K.A., Hughes, S.C., Heigenhauser, G.J.F., Bradwell, S.N., \& Gibala, M.J. (2005). Six sessions of sprint interval training increases muscle oxidative potential and cycle endurance capacity in humans. Journal of Applied Physiology, 98(6), 1985-1990. https://doi.org/10.1152/japplphysiol.01095.2004 
Creer, A.R., Ricard, M.D., Conlee, R.K., Hoyt, G.L., \& Parcell, A.C. (2004). Neural, metabolic, and performance adaptations to four weeks of high intensity sprint - interval training in trained cyclists. International Journal of Sports Medicine, 25(2), 92-98. https://doi.org/10.1055/s-2004-819945

Driller, M.W., Fell, J.W., Gregory, J.R., Shing, C.M., \& Williams, A.D. (2009). The effects of high-intensity interval training in well-trained rowers. International Journal of Sports Physiology and Performance, 4(1), 110-121, 2009.

Esfarjani, F., \& Laursen, P.B (2007). Manipulating high-intensity interval training: effects on $\dot{V}_{2 \max }$, the lactate threshold and $3000 \mathrm{~m}$ running performance in moderately trained males. Journal of Science and Medicine in Sport 10(1), 27-35. https://doi.org/10.1016/j.jsams.2006.05.014

Farzad, B., Gharakhanlou, R., Agha-Alinejad, H., Curby, D.G., Bayati, M., Bahraminejad, M., \& Mäestu, J. (2011). Physiological and performance changes from the addition of a sprint interval program to wrestling training. Journal of Strength and Conditioning Research, 25(9), 2392-2399. https://doi.org/10.1519/JSC.0b013e3181fb4a33

Gibala, M.J., Little, J.P., van Essen, M., Wilkin, G.P., Burgomaster, K.A., Safdar, A., Raha, S., \& Tarnopolsky, M.A. (2006). Short-term sprint interval versus traditional endurance training: similar initial adaptations in human skeletal muscle and exercise performance. Journal of Physiology, 575 ( $\mathrm{Pt}$ 3), 901-911. https://doi.org/10.1113/jphysiol.2006.112094

Gist, N.H., Fedewa, M.V., Dishman, R.K., \& Cureton, K.J. (2014). Sprint interval training effects on aerobic capacity: a systematic review and meta-analysis. Sports Medicine, 44(2), 269-279. https://doi.org/10.1007/s40279-013-0115-0

Karahan, M. (2012). The effect of skill-based maximal intensity interval training on aerobic and anaerobic performance of female futsal players. Biology of sport 9, 223-227. https://doi.org/10.5604/20831862.1003447

Laffite, L.P., Mille-Hamard, L., Koralsztein, J.P., \& Billat, V.L. (2003). The effects of interval training on oxygen pulse and performance in supra-threshold runs. Archives of Physiology and Biochemistry, 111(3), 202-210. https://doi.org/0.1076/apab.111.3.202.23455

Laursen, P.B., Shing, C.M., Peake, J.M., Coombes, J.S., \& Jenkins, D.G. (2002). Interval training program optimization in highly trained endurance cyclists. Medicine and Science in Sports and Exercise, 34(11), 1801-1807. https://doi.org/10.1249/01.MSS.0000036691.95035.7D

Laursen, P.B., Blanchard, M.A., \& Jenkins, D.G. (2002b). Acute high-intensity interval training improves Tvent and peak power output in highly trained males. Canadian Journal of Applied Physiology, 27(4), 336-348.

Léger, L.A., \& Lambert, J. (1982). A maximal multistage 20-m shuttle run test to predict $\mathrm{VO}_{2 \max }$. European Journal of Applied Physiology, 49(1), 1-12.

MacDougall, J.D., Hicks, A.L., MacDonald, J.R., McKelvie, R.S., Green, H.J., \& Smith, K.M. (1998). Muscle performance and enzymatic adaptations to sprint interval training. Journal of Applied Physiology, 84(6), 2138-2142.

Oliveira, R.S., Leicht, A.S., Bishop, D., Barbero-Álvarez, J.C., Nakamura, F.Y. (2013). Seasonal changes in physical performance and heart rate variability in high level futsal players. International Journal of Sports Medicine, 34(5), 42430. https://doi.org/10.1055/s-0032-1323720

Paradisis, G.P., Zacharogiannis, E., Mandila, D., Smirtiotou, A., Argeitaki, P., \& Cooke, C.B. (2014). Multi-Stage 20-m Shuttle Run Fitness Test, Maximal Oxygen Uptake and Velocity at Maximal Oxygen Uptake. Journal of Human Kinetics, 41, 81-87. https://doi.org/10.2478/hukin-2014-0035

Rodas, G., Ventura, J.L., Cadefau, J.A., Cussó, R., \& Parra, J. (2000). A short training programme for the rapid improvement of both aerobic and anaerobic metabolism. European Journal of Applied Physiology, 82(5-6), 480-486. https://doi.org/10.1007/s004210000223

Rowan, A.E. (2012). Short duration high-intensity interval training improves aerobic conditioning of female college soccer players. International Journal of Exercise Science, 5(3), 232-238.

Sheykhlouvand, M., Gharaat, M., Bishop, P., Khalili, E., Karami, E., \& Fereshtian, S. (2015). Anthropometric, Physiological, and Performance Characteristics of Elite Canoe Polo Players. Psychology \& Neuroscience 8, 257-266.

Smith, T.P., McNaughton, L.R., \& Marshall, K.J. (1999). Effects of 4-wk training using Vmax/Tmax on $\dot{V}_{2 \max }$ and performance in athletes. Medicine \& Science in Sports and Exercise. 31(6), 892-896.

Stangier C, Abel T, Hesse C, Claen S, Mierau J, Hollmann W, et al. (2016). Effects of Cycling vs. Running Training on Endurance Performance in Preparation for Inline Speed Skating. Journal of Strength and Conditioning Research, 30(6):1597-1606. https://doi.org/10.1519/JSC.0000000000001247.

Van Cutsem, M., Duchateau, J., \& Hainaut, K. (1998). Changes in single motor unit behavior contribute to the increase in contraction speed after dynamic training in humans. Journal of Physiology, 513 (Pt 1), 295-305. 